\title{
When Everything goes wrong Make a Diagram
}

\author{
Maria Rosaria Digregorio \\ De Montfort University, Leicester Media School, Faculty of Technology, \\ The Gateway, Leicester, LE1 9BH, United Kingdom \\ Maria.Digregorio@dmu.ac.uk
}

\begin{abstract}
Looking at historical examples, this research explores the power of diagrams and visual reasoning. It focuses on their ability to make knowledge more accessible, train critical thinking and trigger a form of intellectual resistance in a post-truth world; it encourages a deeper integration between diagrams and writing, and the diffusion of information design approaches outside the design realm.
\end{abstract}

Keywords: post-truth / diagrammatic reasoning / non-linear writing / visual rhetoric

\section{Introduction}

In 2016 Oxford Dictionaries declared 'post-truth' word of the year. The adjective is defined as 'relating to or denoting circumstances in which objective facts are less influential in shaping public opinion than appeals to emotion and personal belief'. The choice acknowledged a spike in frequency in the context of the EU referendum in the United Kingdom and the presidential election in the United States. Since then, the word became even more mainstream, extending its meaning from an isolated quality of particular assertions to a general characteristic of the current age. One year later the winning word for Collins Dictionary was 'fake news', defined as 'false, often sensational, information disseminated under the guise of news reporting', reinforcing the perception of a dismal context.

This trend seems to suggest that when dealing with the challenging task of communicating complexity, presenting information in a clear and accessible way is not a common practice because is not perceived as an effective strategy - it works better confusing and encouraging irrationality.

Political interests have often preferred propaganda to actual facts, but the recent developments have aroused the doubt that this is a lot bigger than just the political sphere: there is too much information out there, it is very easy to spread fake news and it is very hard for people discerning what is true and what is not - it becomes easier opting for slogans rather than composite facts.

How can information designers - and the whole humankind - cope with such a scenario, where making the effort of understanding and communicating complexity seems overwhelming and almost useless? A possible answer is making diagrams - 
focusing on visualising reasoning and trying to reclaim the power of logical thinking and good argumentation. It might feel a small action, but diagrams are actually really powerful.

\section{The Power of Diagrams}

Visual inferences. In math and geometry, visual configurations are used as proper inferences to demonstrate the validity of reasoning - for instance in the case of the Pythagoras's Theorem and the binomial theorem. Despite written words or notations can also be used to visually represent theorems, the diagram is able to show at glance the reasons behind the rule (Perondi, 2012).
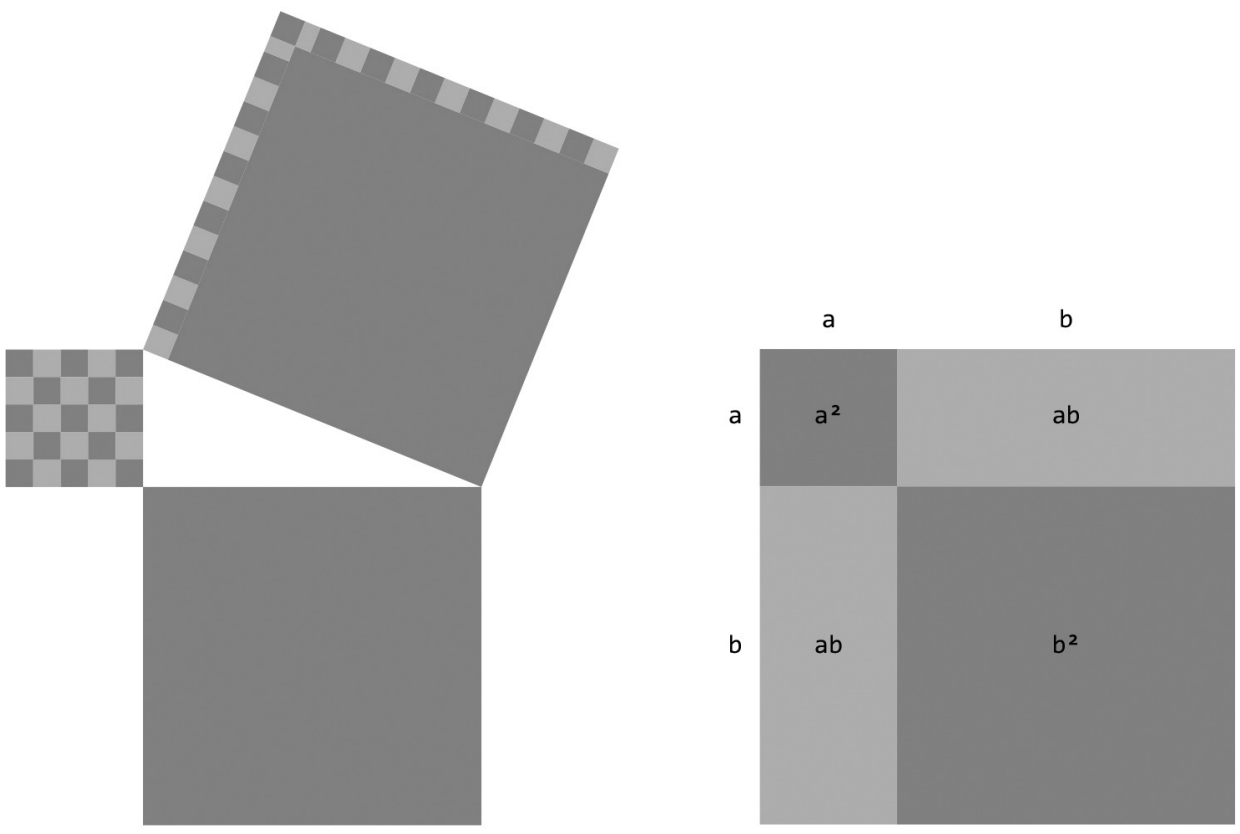

Fig. 1. Pythagoras's Theorem. The square of the hypotenuse is equal to the sum of the squares of the other two sides $\left[a^{2}+b^{2}=c^{2}\right]$. In Digregorio, M. R. (2010), Tipografia delle relazioni logiche. Rappresentazione tipografica della struttura del ragionamento. Master Thesis, Università IUAV di Venezia, Venice, Italy, p. 16.

Fig. 2. Binomial Theorem. A squared binomial is equal to the square of the first term, plus the double of the product of the first by the second plus the square of the second term $\left[(a+b)^{2}=\right.$ $\left.a^{2}+2 a b+b^{2}\right]$. In Digregorio, M. R. (2010), Tipografia delle relazioni logiche. Rappresentazione tipografica della struttura del ragionamento. Master Thesis, Università IUAV di Venezia, Venice, Italy, p. 16. 
Following the same principle, Oliver Byrne designed a version of The Elements of Euclid 'in which coloured diagrams and symbols are used instead of letters for the greater ease of learners' as stated in the subtitle. Words, notation and diagrams are hybridised in a non-linear configuration in which reasoning is demonstrated through visual deduction.

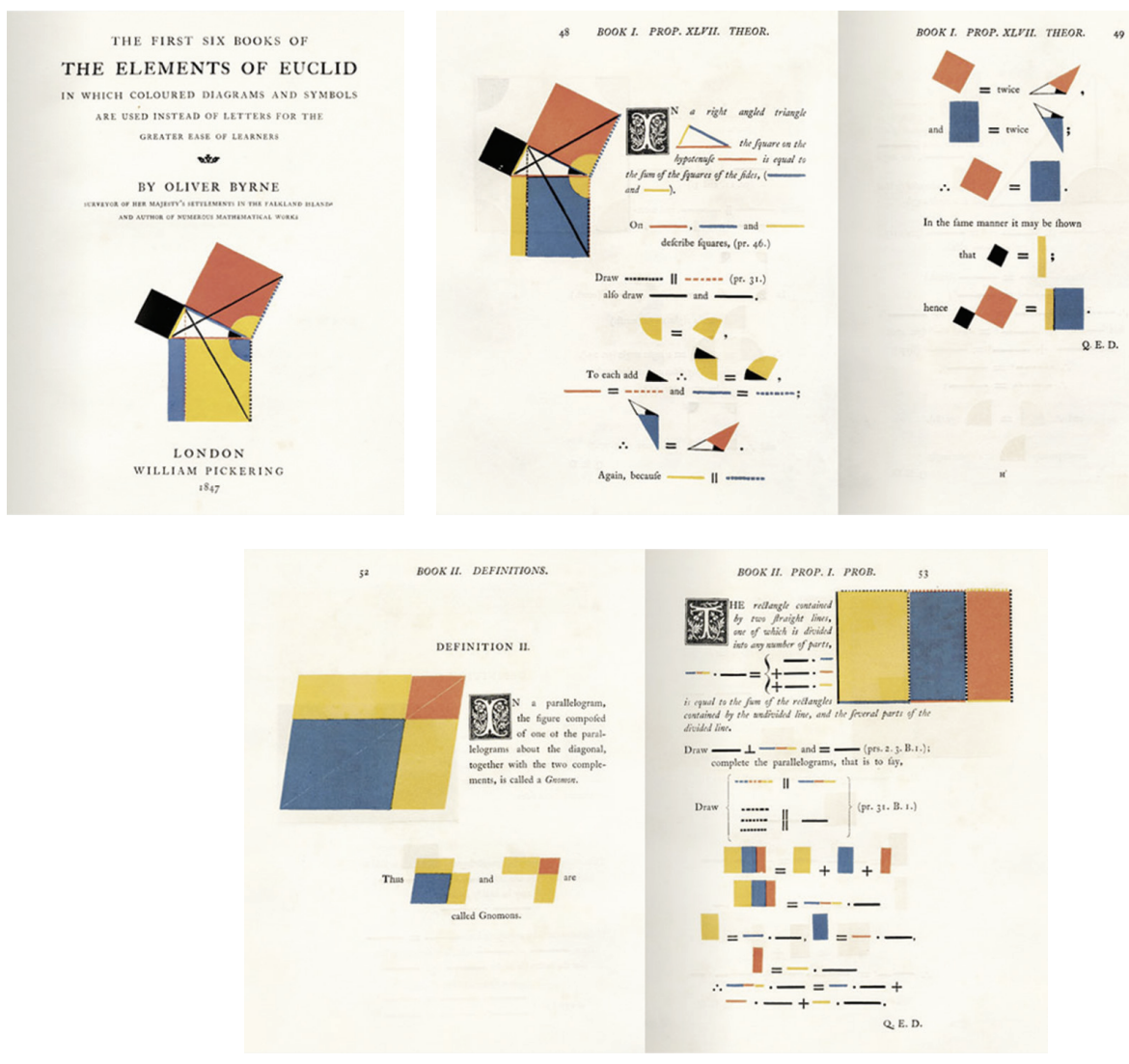

Fig. 3. Byrne, O. (1847), The First Six Books of the Elements of Euclid, in which coloured diagrams and symbols are used instead of letters for the greater ease of learners. London, United Kingdom: William Pickering, title page, pp. 48-49 and pp. 52-53.

In logic, diagrams have been used since Aristotle to visualise the argumentative structure of reasoning, both with analytic and didactic intents - like in the case of Euler diagrams, the closed shapes used to visualise syllogisms. According to their famous inventor, Leonard Euler, these diagrams are extremely useful to facilitate reflection as they allow to make implicit relationships visible (Bagni, 2007). 

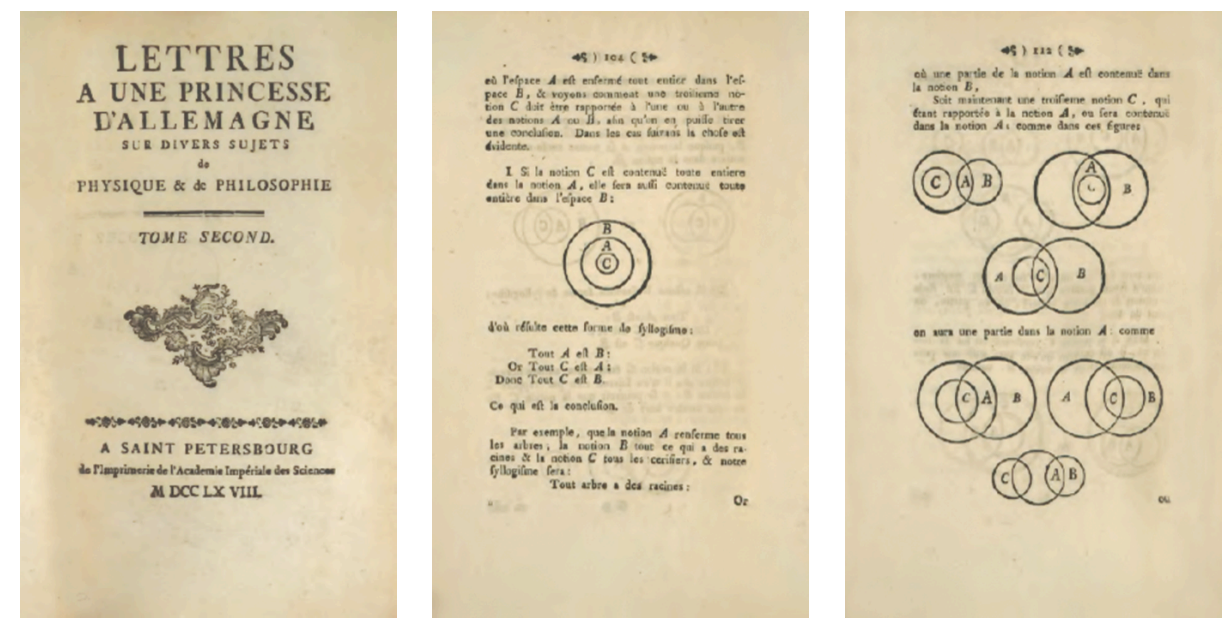

Fig. 4. Euler, L. (1768). Lettres a une princesse d'Allemagne sur divers sujets de physique \& de philosophie. Saint Petersburg, Russia: Académie Impériale des Sciences, title page, p 104 and p.112.

With a similar intent, renowned author of Alice in Wonderland, Lewis Carroll, designed a diagram-based game to teach children the fundamentals of logic. Premises and conclusions are displayed on two related matrices by correctly positioning the coloured tokens, showing immediately which are the valid conclusions given specific premises.
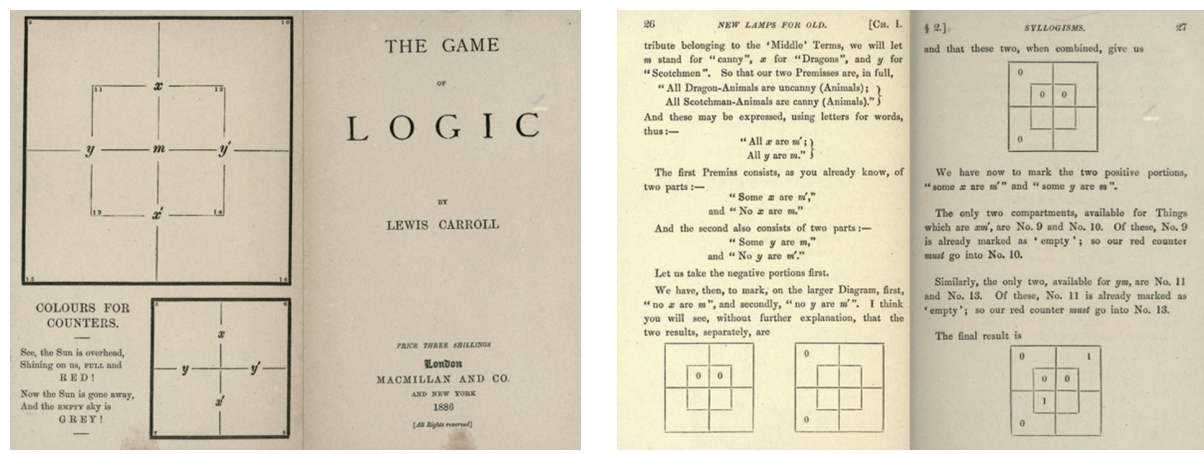

Fig. 5. Carroll, L. (1886), The Game of Logic. London, United Kingdom and New York, United States: Macmillan, title page with diagrams and pp. 26-27. 
Visual analogies. In science, the attribution of a particular configuration to a specific phenomenon is comparable to a real discovery - the hexagonal structure of organic compounds, the double helix of DNA, the inverted tree of evolution, or the concentric circles of the solar system (Anceschi, 1992).

Greek and Roman speakers, instead, used a diagram-based technique to better remember reasoning. Known as the method of loci (loci being Latin for 'places') or memory palace, this 'mnemotechnic' would create a correspondence between the shape of architectural structures and the sequence of arguments in a speech (Yates, 1966).
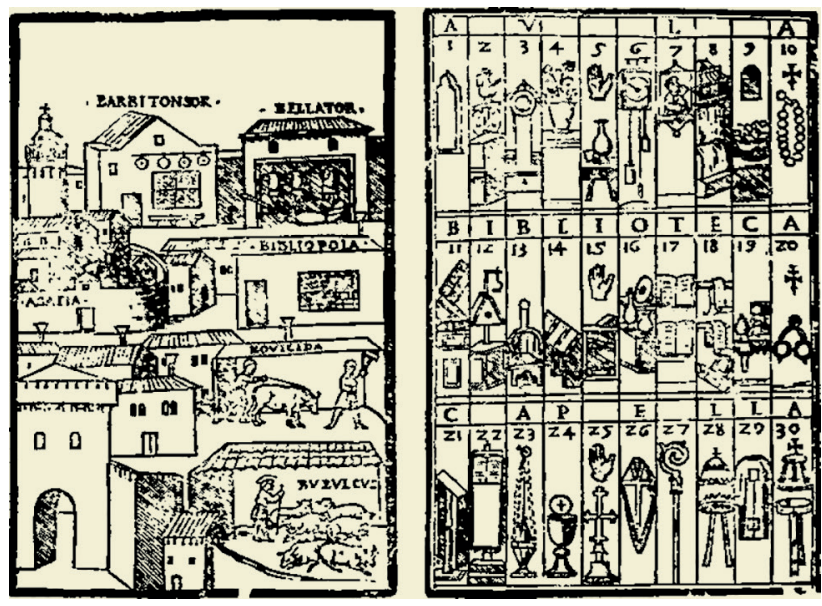

Fig. 6. Abbey Memory System (left) and images to be used in the Abbey Memory System (right) from Johannes Romberch, Congestorium Artificiose Memorie (1533). In: Yates, F. (1966), The Art of Memory. London, United Kingdom \& New York, United States: Routledge and Kegan Paul, p. 112.

Non-linear Writing. Even the written word - which is almost always regarded as a mere reference for visual representations, like the spoken word - when articulated in a non-linear and visually meaningful way, can work as a diagram and be able to represent directly the structure of reasoning (Lussu, 2007). Handwritten notes, postit boards, mind maps, are all examples of the diagrammatic nature of writing and how it offers a practical support to organise thoughts and make decisions.

Diagrammatic Reasoning. According to philosopher and logician Charles Sanders Peirce, good reasoning is related to strong visual images. Peirce considered diagrams not only a tool to divide reasoning into small parts and facilitate logical analysis, but above all a strategy to make mental experiments on thoughts like if they were concrete things, facilitating manipulation and discovery (1980). He elaborated the concept of 'diagrammatic reasoning', a thinking that is made of visual structures, ultimately affirming that there is no reasoning that does not have the nature of the diagrammatic reasoning (2005). 
Peirce's position remarks once more that diagrams provide at different degrees the advantages of making reasoning easier to analyse, manipulate and remember. They allow to anchor the reflection to a concrete support and examine all logical implications in a more rigorous and systematic way than abstract speculation. They allow to access knowledge through their ability to simplify complexity and unfold hidden connections. It is for all these reasons that they are one of most powerful tools to defuse post-truth.

\section{The Rhetoric of Neutrality}

Focusing on visualising reasoning and taking advantage of the diagrams' ability to communicate complexity can be a strategy for designers to navigate the intricacy of an information overloaded world. Nevertheless, pure information is just an abstraction and every representation embeds a rhetoric intent which starts with the design process, even when the intention of the designer is to be as objective as possible (Bonsiepe, 1999).

In his essay The Rhetoric of Neutrality, design critic Robin Kinross (1999) invites to avoid the simplistic distinction between design for information (information design) and design for persuasion (advertising or propaganda) and argues that even the most 'functional' typographic choices are never neutral, they always communicate something else about the designer, the client, the context and, in conjunction with all the other visual variables, they work as 'rhetoric devices'.

Type designer Gerard Unger (2007) goes even further suggesting to think about typography as a 'rhetoric toolkit' that should be part of everyone's learning in order to become more aware of how to visualise reasoning effectively through writing. If also diagrams and non-linear writing approaches were considered part of the same learning pack, it would be possible to shape an infographic toolkit able to enrich everyone's visual vocabulary and increase exponentially the ability to read and conceive complex visualisations, blurring the boundaries between writing and information design.

\section{Conclusion}

The power of diagrams relies on their ability to make complexity more accessible and accustom to logical reasoning, which makes them a crucial tool for design and education. However, even the best intentions of social commitment cannot avoid rhetorical infiltration. Therefore, aiming at communicating complexity is not enough for designers. In order to ensure a more autonomous access to knowledge, it is also necessary to spread the means to visualise information outside the realm of design. Only by encouraging the direct use of diagrams and the personal interpretations of 
information, it will be possible to trigger an intellectual resistance to the loss of trust in good reasoning and, hopefully, welcome a new wave of critical thinking.

\section{References}

Anceschi, G. (1992). L'oggetto della raffigurazione. Milan, Italy: Etas.

Bagni, G. T. (2007). Rappresentare la matematica. Rome, Italy: Aracne.

Bonsiepe, G. (1999). Visual/Verbal Rhetoric. In Bierut, M., Helfand, J., Heller, S., \& Poynor, R. (Eds.), Looking closer 3. Classic writings on graphic design. New York, United States: Allworth Communications.

Digregorio, M. R. (2011), Gli Elementi di Byrne e il ruolo del diagramma nella didattica della matematica. In Progetto Grafico, volume 20, Milan, Italy: AIAP.

Kinross, R. (1989), The Rhetoric of Neutrality. In Margolin, V. (Ed.), Design Discourse. Chicago, United States: University of Chicago Press.

Lussu, G. (2007), Tipografia e oltre. In V. Bucchetti (Ed.), Culture visive. Contributi per il design della comunicazione. Milan, Italy: Poli.design.

Peirce, C. S. (2005), Pensiero e scrittura, MS 956. In Marietti, S. (Ed.) Un passo inedito dai quaderni del filosofo circa il rapporto tra pensiero e scrittura. Riproduzione del manoscritto, testo inglese, traduzione italiana e introduzione, Rivista di filologia cognitiva, volume 3. Retrieved from: http://filologiacognitiva.let.uniroma1.it/peircei.html

Peirce, C. S. (1980), Semiotica. Torino, Italy: Einaudi.

Perondi, L. (2012), Sinsemie. Scritture nello spazio. Rome, Italy: Stampa alternativa e Graffiti.

The Collins Word of the Year 2017 is... (2017, November).

Retrieved from: http://www.collinsdictionary.com/woty

Unger, G. (2007), Typography as (Vehicle of) Science. Amsterdam, Netherlands: De Buitenkant. Word of the Year 2016 is... (2016, November).

Retrieved from: http://en.oxforddictionaries.com/word-of-the-year/word-of-the-year-2016

Yates, F. (1966), The Art of Memory. London, United Kingdom \& New York, United States: Routledge and Kegan Paul. 